\title{
Perancangan Sistem Aplikasi Koperasi Karyawan di Politeknik Negeri Jakarta
}

\author{
Siti Kulsum Suryana Putri, Dwi Rizkyanti, Rohimam, Muhammad Fikri \\ Program Studi Teknik Informatika Jurusan Teknik Informatika dan Komputer \\ Politeknik Negeri Jakarta \\ sitikulsumpsuryana@gmail.com,dwirizkiyanti.dr@gmail.com, rohimamgunawan@yahoo.co.id, \\ mfikri351@yahoo.com
}

Diterima: 8 Mei 2017. Disetujui 20 Mei 2017. Dipublikasikan Mei 2017

\begin{abstract}
Abstrak - Saat ini penginputan dan pengolahan data pada Koperasi Karyawan di Politeknik Negeri Jakarta (PNJ) masih menggunakan metode manual yaitu pembukuan. Metode pembukuan dianggap kurang efektif karena mudah rusak dan hilang serta pembuatan laporannya memakan waktu lama. Salah satu hal yang menyebabkan masih digunakannya metode manual ini yaitu belum adanya aplikasi yang dapat membuat sistem tersebut dan sebagian staff karyawan koperasi masih awam dengan teknologi komputer. Maka dibutuhkan solusi berupa sistem aplikasi untuk penanganan olah dan input data yang baik dan benar dengan sistem yang user friendly. Metode penelitian yang digunakan untuk pengumpulan data yaitu dengan cara melakukan wawancara dengan narasumber terkait yang merupakan pengurus dari koperasi karyawan tersebut. Metode perancangan sistem menggunakan prototype dengan alat perancangan berupa Use Case Diagram, ERD (Entity Relationship Diagram), Activity Diagram, Class Diagram dan Deployment Diagram. Untuk implementasi program dengan UI (User Interface) yang dibuat menggunakan Visual Basic. Dengan Sistem Aplikasi Koperasi Karyawan ini diharapkan agar penginputan dan pengolahan data-data yang selama ini masih tersimpan dan dikelola secara manual dapat segera mulai menggunakan sistem komputerisasi sehingga dapat lebih mengefektifkan kinerja para karyawan koperasi dalam menjalankan kegiatan dan tugas-tugas yang berhubungan dengan koperasi.
\end{abstract}

Kata Kunci: sistem aplikasi, ERD, use case diagram, class diagram, koperasi, visual basic.

\section{PENDAHULUAN}

Koperasi adalah suatu perkumpulan orang, biasanya yang memiliki kemampuan ekonomi terbatas [1], yang melalui suatu bentuk organisasi perusahaan yang diawasi secara demokratis [2], masing-masing memberikan sumbangan yang setara terhadap modal yang diperlukan [3], dan bersedia menanggung risiko serta menerima imbalan yang sesuai dengan usaha yang mereka lakukan [4]. Penjelasan koperasi di Indonesia tertuang dalam UU No. 25 Tahun 1992 yang berbunyi "koperasi adalah badan usaha yang beranggotakan orang-orang atau badan hukum koperasi dengan melandaskan kegiatannya berdasarkan prinsip koperasi, sekaligus sebagai gerakan ekonomi rakyat yang berdasarkan asas kekeluargaan [5]”. Dari dua definisi tersebut dapat ditarik kesimpulan bahwa koperasi merupakan kumpulan orang-orang berekonomi lemah yang dengan sukarela melakukan kerja sama di bidang ekonomi yang bertujuan untuk memenuhi kebutuhan para anggotanya dengan berasaskan kekeluargaan.

Hingga saat ini koperasi masih dianggap sebagai salah satu kegiatan ekonomi yang dibutuhkan oleh masyarakat [6] dalam meningkatkan kehidupan di bidang ekonomi sehingga dapat dikatakan bahwa koperasi termasuk ke dalam aset ekonomi [7]. Dengan meningkatnya teknologi, sistem komputasi manual banyak beralih ke sistem komputasi dinamis dengan alasan untuk mempermudah menyelesaikan pekerjaan yang banyak dengan waktu singkat [8]. Hal itu berlaku pula pada perkoperasian. Sistem komputasi dinamis sangat dibutuhkan dalam proses olah data di koperasi [9].

Untuk itu dilakukan penelitian dan perancangan sistem komputasi berbasis aplikasi untuk Koperasi Karyawan di Politeknik Negeri Jakarta (PNJ). Penelitian dan perancangan ini bertujuan untuk memudahkan penginputan dan pengolahan data-data pada koperasi yang selama ini masih tersimpan dan 
dikelola secara manual. Manfaat dari penelitian ini yaitu untuk merancang sistem komputasi berbasis aplikasi yang dapat meminimalkan waktu komputasi dan mengefektifkan kinerja karyawan dalam melakukan tugas dan kegiatan yang berhubungan dengan koperasi sehingga konsumsi terhadap kertas akan berkurang.

\section{MEtodologi PENELITIAN}

Pelaksanaan penelitian ini dilakukan dengan kegiatan sebagai berikut.

a. Studi Literatur

Mempelajari tentang koperasi secara umum.

b. Wawancara

Melakukan wawancara dengan salah satu karyawan yang melakukan olah data manual di koperasi karyawan PNJ.

c. Persiapan Data/Analisa Kebutuhan Sistem

Penelitian ini menggunakan langkah-langkah Object Oriented Analysis and Design.

d. Perancangan Sistem

Dari penelitian yang telah dilakukan, dibuatlah rancangan menggunakan Enterprise Architect 8 sebagai media pengaplikasian dalam pembuatan diagram-diagram yang dibutuhkan.

e. Implementasi penerapan diagram

Proses penerapan dari diagram yang telah dibuat ke dalam desain model User Interface dengan menggunakan Microsoft Visual Basic 6.0 .

\section{HASIL DAN PEMBAHASAN}

1. Analisis Kebutuhan Sistem

Setelah melakukan observasi berupa wawancara di Koperasi Karyawan PNJ diperoleh kendala dalam hal pembukuan yaitu pencatatan data, penginputan data dan pengolahan data masih dilakukan secara manual. Dimana pembuatan laporan dan penginputan harga serta stok barang dilakukan secara manual oleh karyawan yang bertugas sebagai operator pengolah data-data yang masuk dan keluar dengan menggunakan software Ms.Office yaitu Ms.Excel. Pembuatan secara manual ini terkadang membuat operator yang bertugas kewalahan ketika harus merekap data-data dari bulan-bulan sebelumnya karena terlalu banyak file yang dibuat sehingga kurang terstruktur ketika akan dilakukan pembukuan data bahkan data rentan hilang karena hanya tersimpan di dalam media penyimpanan komputer. Oleh karena itu didapatkan solusi untuk mengatasi permasalahan tersebut yaitu perlu dibuatnya perancangan sistem aplikasi koperasi karyawan di Politeknik Negeri Jakarta guna meminimalkan waktu komputasi, kinerja karyawan dan menghasilkan output dari proses yang dikerjakan serta meminimalkan kehilangan data dengan adanya media penyimpanan database dari aplikasi.

\section{Desain Sistem}

Dalam rangka optimalisasi perancangan sistem aplikasi koperasi karyawan di PNJ dibuatlah desain sistem berdasarkan analisa yang telah dilakukan diatas. Maka dari itu dibutuhkan upaya untuk merancang sistem tersebut secara terkomputerisasi agar dapat mengoptimalkan sistem aplikasi yang akan dibuat sehingga dapat mencapai hasil yang maksimal dalam pemakaiannya. Ada 5 perangkat yang digunakan dalam perancangan sistem aplikasi ini yaitu: Use Case Diagram, Activity Diagram, Class Diagram, Entity Relationship Diagram (ERD), dan Deployment Diagram.

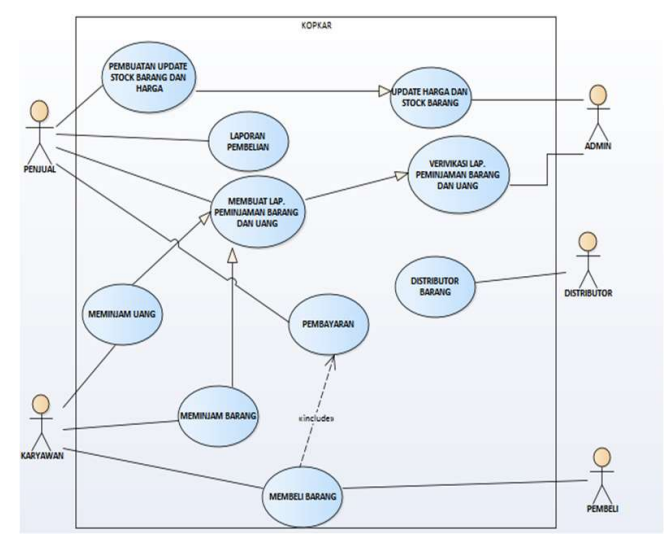

Gambar 1. Use Case Diagram Koperasi Karyawan PNJ

Pada diagram Use Case di Gambar 1 dapat dijelaskan jika karyawan dapat melakukan peminjaman barang, peminjaman uang, dan membeli barang. Pada proses membeli barang terdapat hubungan dengan pembeli dimana pembeli juga dapat melakukan proses yang sama. Proses ini sudah include ke dalam proses pembayaran dimana yang akan menangani proses tersebut adalah penjual. Sementara untuk proses peminjaman barang dapat langsung berhubungan dengan proses membuat laporan peminjaman barang dan uang. Setiap peminjam yang melakukan transaksi peminjaman akan dicatat oleh penjual untuk dijadikan laporan dan akan disimpan didalam database. Penjual juga melakukan pembuatan 
update stok dan harga barang yang nantinya akan divalidasi dan disimpan di database oleh admin. Penjual juga akan membuat laporan untuk pembelian dan juga untuk pembayaran. Sementara itu admin melakukan validasi data, seperti data update stok dan harga barang sebelum disimpan di database serta memvalidasi laporan peminjaman barang dan uang. Pada use case, distributor hanya melakukan proses pendistribusian barang sehingga tidak memiliki hubungan kemanapun.

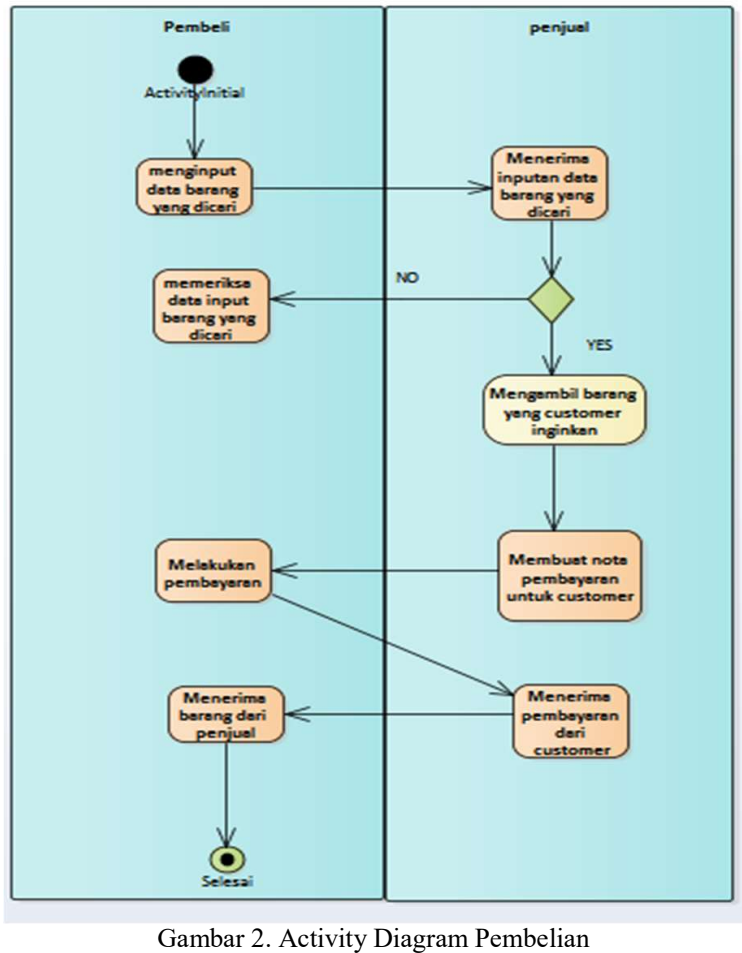

Pada Gambar 2, object pembelian yang digunakan adalah pembeli dan penjual. Pembeli melakukan penginputan data barang yang dicari. Setelah itu penjual akan menerima inputan data barang yang dicari. Sistem akan memvalidasi jika data yang diinput benar maka penjual akan mengambil barang yang customer inginkan. Jika tidak, maka user atau customer harus memeriksa data input barang yang dicari atau harus menginput data barang itu kembali. Setelah mengambil barang yang diinginkan customer, penjual akan membuat nota pembayaran untuk pembeli. Selanjutnya pembeli melakukan pembayaran, penjual menerima pembayaran dari customer, dan customer akan menerima barang dari penjual.

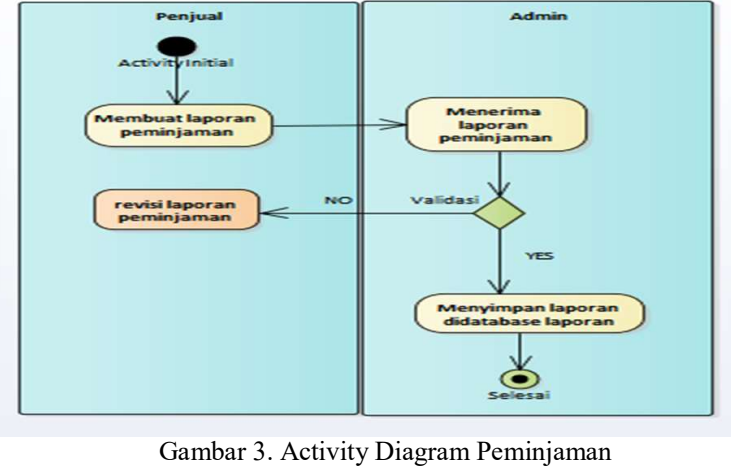

Pada activity diagram peminjaman di Gambar 3, karyawan akan mengisi form peminjaman uang atau barang. Penjual akan menerima data form peminjaman untuk dilakukan validasi. Jika benar, penjual akan menginput data peminjam ke laporan peminjaman dan karyawan menerima bukti laporan peminjaman customer. Jika tidak, maka karyawan akan memeriksa kembali form laporan peminjaman.

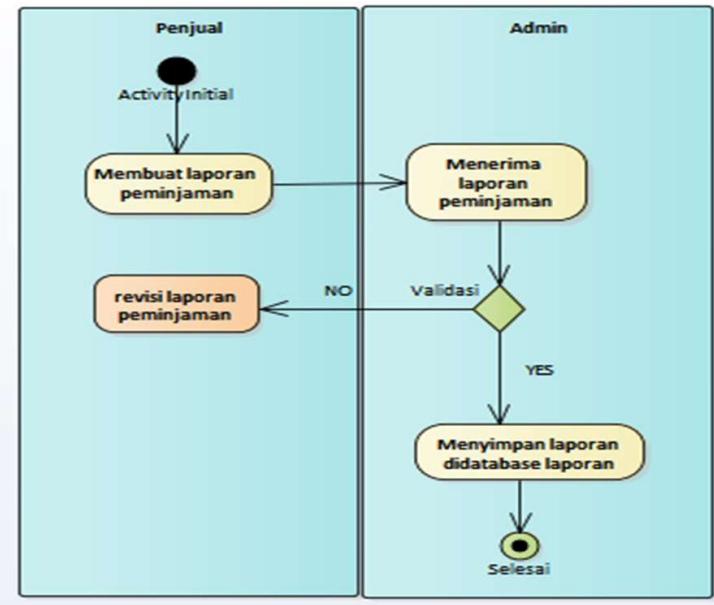

Gambar 4. Activity Diagram Laporan Peminjaman

Pada Gambar 4 terdapat object penjual dan admin. Penjual membuat laporan peminjaman yang akan diterima oleh admin dan divalidasi sistem. Jika laporan penjualan benar dan tanpa kesalahan maka data laporan penjualan akan disimpan di database laporan. Namun jika masih ada kesalahan maka harus dilakukan revisi laporan peminjaman. 


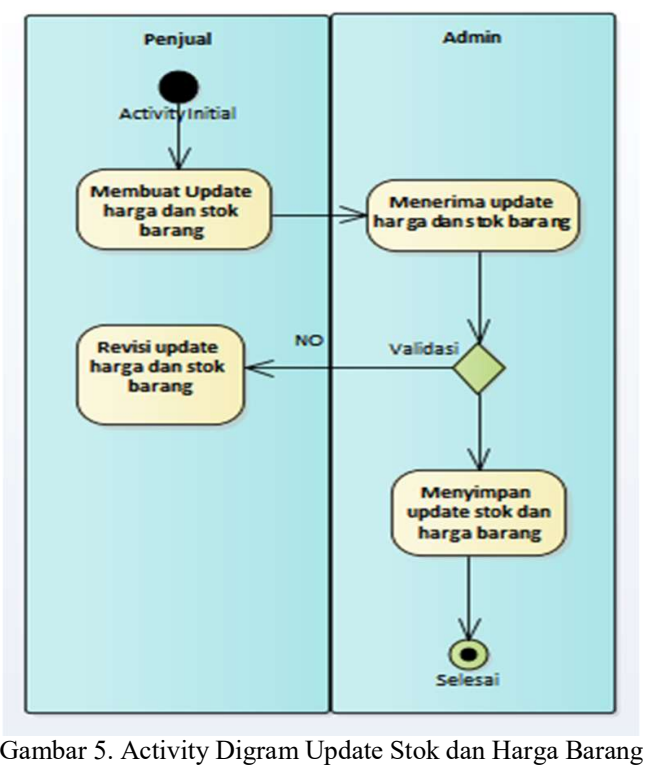

Pada Gambar 5 digunakan 2 object yaitu penjual dan admin. Penjual membuat update harga dan stok barang yang akan diterima oleh admin dan divalidasi. Jika benar, maka update stok dan harga barang akan disimpan, jika tidak maka harus diperiksa kembali atau direvisi.

Class Diagram pada Gambar 6 menjelaskan adanya beberapa aktor dan proses yang ada pada sistem aplikasi koperasi karyawan. Aktor yang berperan adalah distributor, admin, karyawan, pembeli dan penjual. Beberapa proses yang terdapat di sistem adalah update stok dan harga barang, memvalidasi laporan, melakukan distributor barang, meminjam uang, meminjam barang, membeli barang dan melakukan pembayaran.

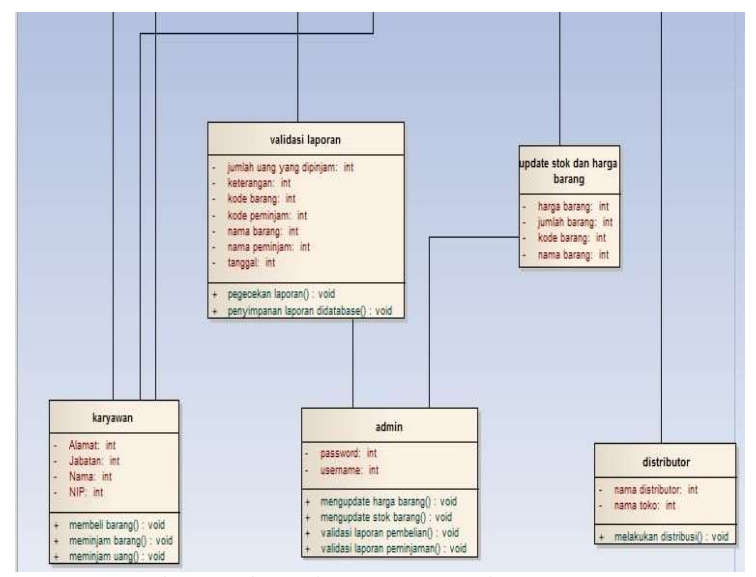

Gambar 6. Class Diagram Koperasi Karyawan PNJ

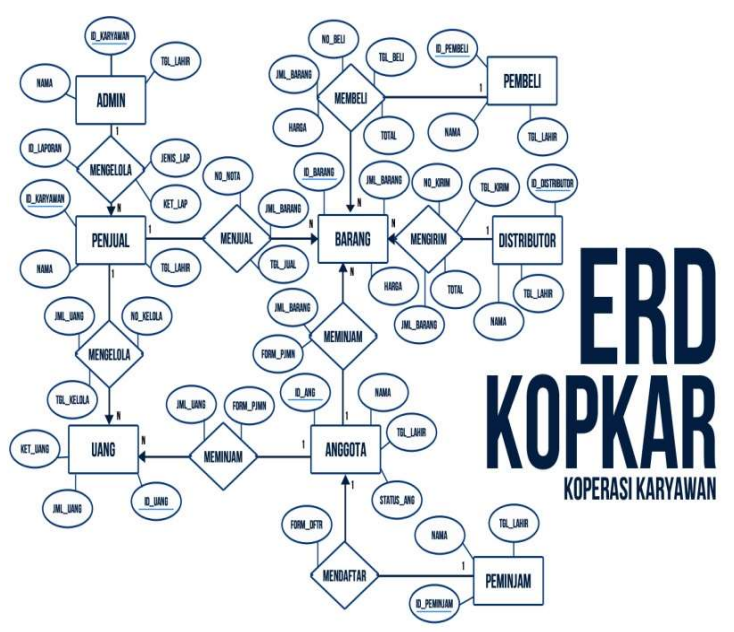

Gambar 7. Entity Relationship Diagram Koperasi Karyawan PNJ

Pada ERD diagram dapat dijelaskan jika pembeli memiliki atribut nama, id pembeli, dan tgl_lahir. Atribut itu diperlukan hanya saat pertama kali pembeli (mahasiswa atau karyawan) terdaftar di PNJ. Pembeli dapat melakukan pembelian barang sehingga atribut yang diperlukan adalah no_beli, tgl_beli, jnl_barang, harga, dan total. Pembeli dapat membeli barang yang memiliki atribut ID_barang, jml_barang, dan harga. Jika pembeli ingin membeli barang maka akan berhubungan dengan penjual. Penjual akan menjual barang, sehingga terdapat proses menjual. Penjual menjual barang, dengan atribut untuk menjual adalah No_nota tgl_jual, dan jml_barang. Sedangkan atribut untuk penjual adalah ID_karyawan, Nama, Tgl lahir. Penjual juga memiliki proses untuk mengelola laporan peminjaman baik peminjaman uang maupun barang. Untuk atribut proses mengelola laporan peminjaman adalah Jml uang dan form_peminjaman. Untuk atribut pada object uang yang diperlukan adalah ID_uang, Jml_uang, dan Ket uang. Sementara atribut untuk object anggota adalah ID_Ang, Nama, TGL_Lahir, dan Status_Ang. Ketika Anggota meminjam barang maupun uang atributnya adalah form_pjmn, jml_uang, dan jml barang. Pada koperasi karyawan ini barangbarang yang dibutuhkan didapatkan dari distributor yang memiliki atribut ID_Distributor, nama, dan TGL Lahir. Distributor melakukan pengiriman barang dengan atribut yang digunakan ID_kirim, JML_barang, dan Total. Terdapat admin yang menerima laporan dari yang penjual Admin memiliki atribut ID_karyawan, Nama, dan TGL_lahir. Admin 
mengelola laporan dengan atribut ID_Laporan, Jenis_lap, dan Ket_lap. Peminjam harus menjadi anggota agar dapat meminjam uang dan barang dengan ketentuan-ketentuannya. Peminjam memiliki atribut ID_peminjam, nama, dan TGL_lahir. Peminjam mendaftarkan dirinya untuk menjadi anggota dengan membawa atribut form_dftr.

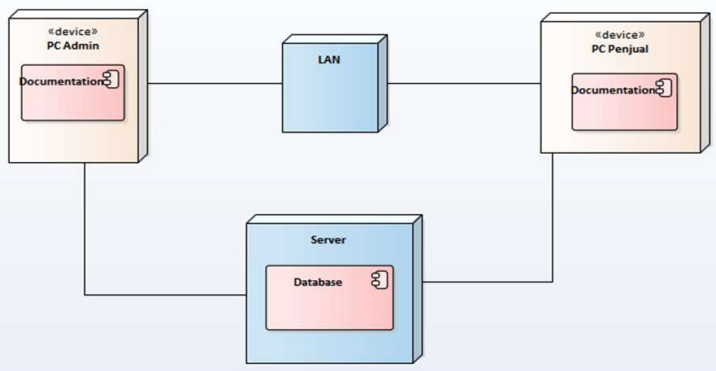

Gambar 8. Deployment Diagram Koperasi Karyawan PNJ

Pada gambar 8 dijelaskan sebuah deployment diagram yang menggambarkan perangkat-perangkat untuk mendistribusikan data atau software pada sistem aplikasi Koperasi Karyawan di PNJ.

Dari hasil analisis dan desain yang telah dilakukan diatas, maka tahapan selanjutnya yaitu melakukan implementasi atau penerapan rancangan desain sistem ke dalam desain model User Interface. Menu utama pada Gambar 3 adalah tampilan awal ketika sistem aplikasi diakses. Form input anggotaanggota koperasi karyawan di PNJ terdapat pada Gambar 10. Form proses penginputan untuk edit dan simpan laporan peminjaman uang ada di Gambar 11. Form proses penginputan untuk edit dan simpan laporan peminjaman barang di Gambar 12. Untuk menginput data peminjam yang berasal dari staf dan anggota karyawan koperasi yang dizinkan melakukan peminjaman digunakan form pada Gambar 13 .

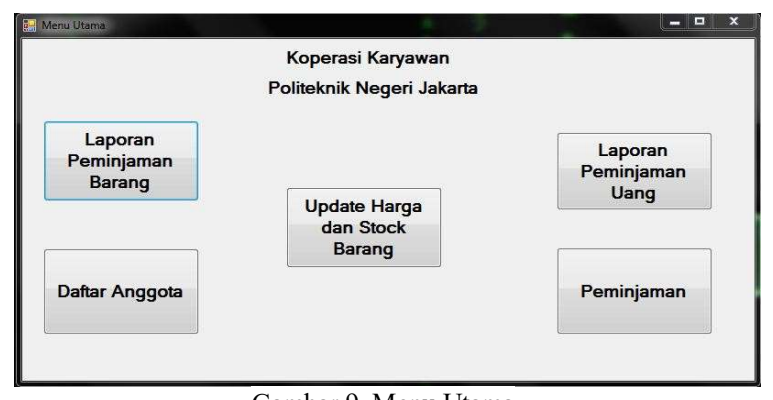

Gambar 9. Menu Utama

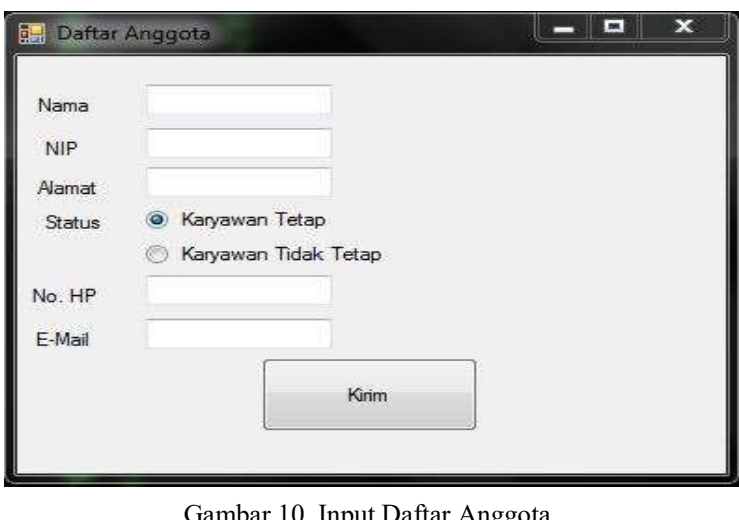

Gambar 10. Input Daftar Anggota

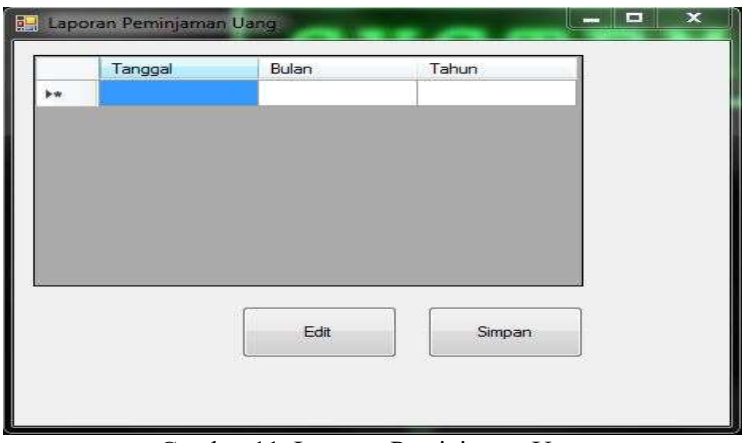

Gambar 11. Laporan Peminjaman Uang

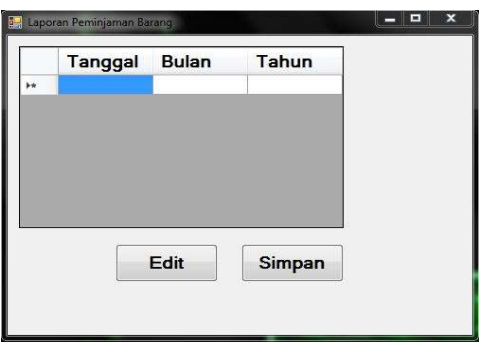

Gambar 12. Laporan Peminjaman Barang

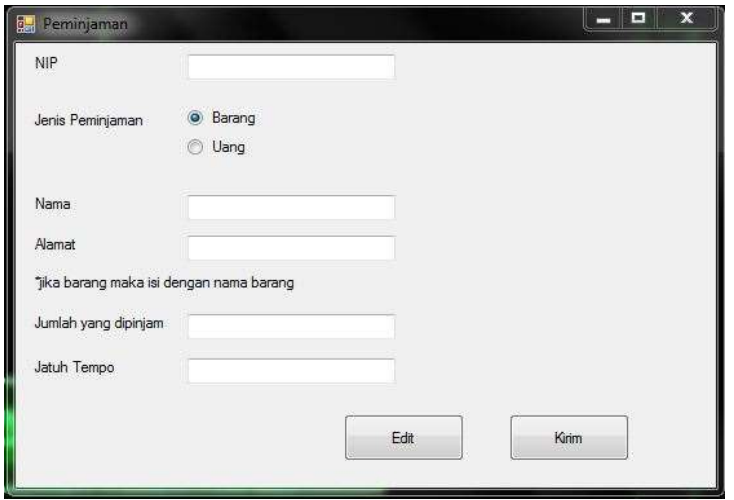

Gambar 13. Peminjaman 
Form untuk mencari update stok dan harga barang yang tersedia di koperasi karyawan PNJ terdapat pada Gambar 14.

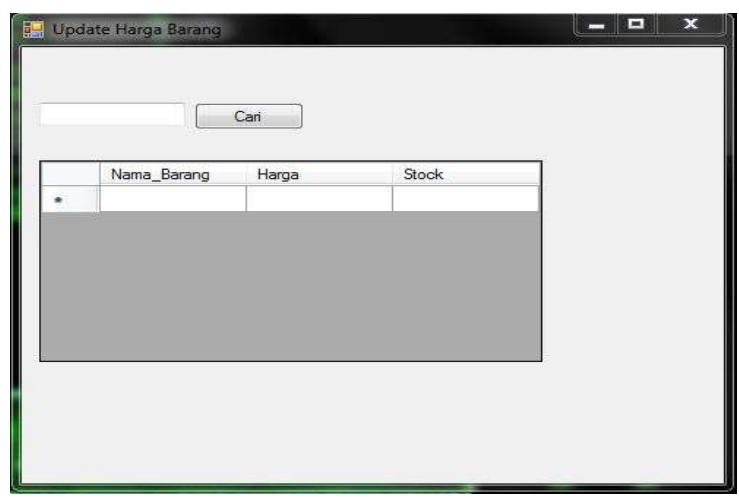

Gambar 14. Update Stok dan Harga Barang

\section{KESIMPULAN DAN SARAN}

Dari hasil penelitian ini dapat diambil beberapa kesimpulan sebagai berikut:

1. Output dari aplikasi berupa laporan peminjaman uang dan laporan peminjaman barang yang dibedakan berdasarkan jenis peminjamannya.

2. Meringkas proses peminjaman yang ketika dilakukan secara manual diperlukan tahapan prosedur dan proses peminjaman yang bertahap yang membutuhkan banyak waktu. Dengan adanya aplikasi kopkar ini prosedur dan proses peminjaman dapat dilakukan bertahap dalam satu waktu.

3. Proses pembukuan koperasi lebih terstruktur.

Namun perlu adanya pengembangan sistem lebih lanjut karena ini adalah sistem pertama yang dibuat untuk koperasi karyawan di Politeknik Negeri Jakarta sehingga masih banyak kekurangan dalam pembuatan sistem aplikasi ini.

\section{REFERENSI}

[1] Afif, Izwar. 2011. Rancangan Bangun Sistem Informas Simpan Pinjam Studi Kasus: Koperasi Simpan Pinjam Ittihadul Mujahirin. Diambil dari: http://repository.uinjkt.ac.id/dspace/bitstream/123456789/163 5/1/IZWAR\%20AFIF-FST.PDF. Diakses pada tanggal 30 Januari 2017.

[2] Ayudya P., Shinta. Sistem Informasi Simpan Pinjam Studi Kasus Pada Koperasi Karyawan PT.Dok\&Perkapalan Surabaya. Diambil dari: http://ejournal.narotama.ac.id/. Diakses pada tanggal 29 Januari 2017.

[3] Hasyim, Nurlaila, Nur Aeni, dan Sarwoto Wijoyo. 2014 Rancang Bangun Sistem Informasi Koperasi Berbasis Web pada Koperasi Warga Baru Mts N 17 Jakarta. Diambil dari: http://download.portalgaruda.org/article.php?article=389322 \&val=329\&title $=$ Rancang $\% 20$ Bangun $\% 20$ Sistem $\% 20$ Inform asi $\% 20$ Koperasi $\% 20$ Berbasis $\% 20 \mathrm{Web} \% 20$ pada $\% 20$ Koperasi $\% 20 \mathrm{Warga} \% 20 \mathrm{Baru} \% 20 \mathrm{MTs} \% 20 \mathrm{~N} \% 2017 \% 20 \mathrm{Jakarta}$. Diakses pada tanggal 30 Januari 2017.

[4] J-TIT.(2016). "Jurnal Teknologi Informasi dan Terapan Vol.02”. http://publikasi.polije.ac.id, Januari 2016.

[5] Puspita Sari, Jenitta Vaulina dan Kirwani. 2015. Studi Tentang Manajemen Pengelolaan Koperasi Karyawan Keluarga Besar Petrokimia Gresik (K3PG). Jurnal Pendidikan Ekonomi (JUPE) Vol 2, No 2, (2014). Diambil dari:

http://ejournal.unesa.ac.id/index.php/jupe/article/view/8102/1 0920. Diakses pada tanggal 30 Januari 2017.

[6] Sartika, Reza dan Daniel Udjulawa. 12 Maret 2015. Perancangan Sistem Informasi Simpan Pinjam Kopkar Mandiri A.Rivai Berbasis Website. Diambil dari: http://eprints.mdp.ac.id/id/eprint/1346. Diakses pada tanggal 29 Januari 2017.

[7] Sevin, Marsha, Teguh Sutanto, dan Erwin Sutomo. September 2015. Analisis dan Desain Sistem Informasi Koperasi Wanita Setia Bhakti Wanita pada Unit Simpan Pinjam JSIKA Vol. 4, No. 2. September 2015. Diambil dari http://jurnal.stikom.edu/index.php/jsika/article/viewFile/844/ 488. Diakses pada tanggal 30 Januari 2017.

[8] Website Repository e-journal Universitas Atmajaya Yogyakarta. [Online]. Diambil dari: http://www.ejournal.uajy.ac.id/. "Jurnal EP217770". Diakses pada tanggal 29 Desember 2016 pukul 8.03 WIB.

[9] Website ePrints@UNY - Lumbung Pustaka Universitas Yogyakarta. [Online]. Diambil dari: http://www.eprints.uny.ac.id/. Jurnal BAB 20II06404241048. Diakses pada tanggal 29 Desember 2016 pukul 8.08 WIB. 